\title{
Sustentabilidade versus legislação vigente: uma análise no perfil das licitações sustentáveis no Tribunal de Justiça de Pernambuco, Brasil
}

\section{Maria de Fátima de Lima Leite ${ }^{1}$, Luiz Filipe Alves Cordeiro $^{2}$, Daniele de Castro Pessoa de Melo $^{2}$ e Ronaldo Ribeiro Barbosa de Aquino ${ }^{3}$}

${ }^{1}$ Instituto de Tecnologia de Pernambuco. Mestrado Profissional em Tecnologia Ambiental. Av. Prof. Luís Freire, 700. Curado. Recife-PE, Brasil (CEP 50740-540).

${ }^{2}$ Instituto de Tecnologia de Pernambuco. Av. Prof. Luiz Freire, 700. Bloco C. Cidade Universitária. Recife-PE, Brasil (CEP 50740-540). E-mail: filipecordeiro@gmail.com.

${ }^{3}$ Universidade Federal de Pernambuco. Centro de Tecnologia. Departamento de Engenharia Elétrica e Sistemas de Potência. Av Acadêmico Hélio Ramos S/№. Cidade Universitária. Recife-PE, Brasil (CEP 50740-530).

Resumo. As licitações sustentáveis têm ganhado cada vez mais espaço nas diretrizes de gestão pública, mesmo que grande parte dos órgãos públicos ainda desconheça ou não faça uso destas práticas. A crescente quantidade de legislações referente às licitações sustentáveis no passar dos anos mostra a importância do tema para os órgãos públicos. 0 objetivo deste trabalho, à luz da legislação vigente, foi verificar os ganhos obtidos com a implementação de critérios socioambientais no Tribunal de Justiça de Pernambuco, mais especificamente no tocante à implementação de tecnologia LED, visando à eficiência energética em iluminação. Após a identificação dos critérios foi feita a análise de como estes podem ser evidenciados de maneira objetiva nos editais de licitações. Posteriormente, foi realizado um estudo de caso para analisar a utilização de critérios socioambientais nos editais de licitações para aquisição de lâmpadas do tipo LED. 0 estudo de caso desenvolvido demonstrou ganhos ambientais, econômicos e sociais para o Tribunal de Justiça de Pernambuco e todos os stakeholders. Espera-se que as licitações sustentáveis sejam a regra e não a exceção em um futuro próximo, contribuindo para as mudanças nos padrões de produção e consumo da sociedade em prol do desenvolvimento sustentável.

Palavras-chave: Licitações sustentáveis; Plano de logística sustentável; Poder público.

Abstract. Sustainability versus legislation in force: An analysis in the profile of sustainable biddings in the Pernambuco Court of Justice. Sustainable bidding has been gaining more and more
Recebido

$07 / 11 / 2020$

Aceito

$20 / 12 / 2020$

Disponível on line $23 / 12 / 2020$

Publicado

$31 / 12 / 2020$

Acesso aberto

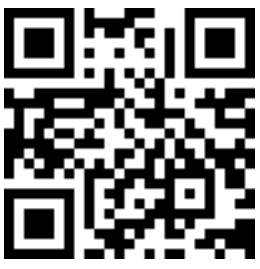

(D) 0000-0003-3875-0758

Maria de Fátima de

Lima Leite

ISSN 2359-1412/RBGAS-2020-0166/2020/7/17/39/1653

Rev. Bras. Gest. Amb. Sustent.

http://revista.ecogestaobrasil.net 
space in the public management guidelines, even though a large part of public agencies still do not know or do not use these practices. The increasing amount of legislation regarding sustainable bidding over the years shows the importance of the issue for public agencies. The objective of this work, in the light of the current legislation, was to verify the gains obtained with the implementation of socio-environmental criteria in the Pernambuco Court of Justice, more specifically with regard to the implementation of LED technology aiming at energy efficiency in lighting. After identifying the criteria, an analysis was made of how they can be evidenced in an objective manner in the bidding documents. Subsequently, a case study was carried out to analyze the use of socio-environmental criteria in the bidding documents for the purchase of LED lamps. The developed case study demonstrated environmental, economic and social gains for the Pernambuco Court of Justice and all stakeholders. Sustainable bidding is expected to be the rule and not the exception in the near future, contributing to changes in society's production and consumption patterns in favor of sustainable development.

Keywords: Sustainable bids; Sustainable logistics plan; Public power.

\section{Introdução}

A sociedade atual tem sido visualizada como uma grande exploradora dos recursos naturais, visto que busca de forma desenfreada a cultura do consumismo e nem sempre atuam de forma a mitigar as consequências negativas desse tido de comportamento. Os progressos da ciência e da tecnologia contribuíram para o aumento da expectativa de vida da população e aumento desta população. Neste contexto, em especial com o começo da industrialização, o aumento econômico ocorre de maneira acelerada impulsionando a produção, utilizando matérias-primas e recursos naturais sem, inicialmente, se preocupar com o esgotamento dos mesmos e o tratamento dos resíduos, provocando a degradação do meio ambiente. Durante muitos anos a sociedade e os governos não se importavam muito com o impacto ambiental gerado pelos produtos que produziam e consumiam. Dessa forma, é urgente a busca por um meio ambiente equilibrado e o poder público deve ser o condutor das políticas públicas voltadas ao zelo pela a "casa comum".

Assim, ao longo das últimas décadas, a percepção dos graves danos causados ao meio ambiente pelo crescimento econômico desenfreado e despreocupado, conduziu as nações mais desenvolvidas a adotarem medidas que proporcionem um desenvolvimento econômico sustentável, preocupado com o meio ambiente e futuras gerações.

Diante dessa perspectiva, a administração pública tem orientado as suas políticas para o atendimento às demandas da sociedade civil em relação ao direito a desenvolvimento em conciliação ao direito a um meio ambiente sadio e equilibrado, ambos considerados direitos fundamentais da pessoa humana.

Constata-se que há um consenso entre vários autores, como Bursztyn (2006), Barbieri (2007), Roncaglio e Janke (2008), Brasil (2016), dentre muitos outros, que não se deve mais manter esse cultura de consumismo desenfreado, sob o risco do meio ambiente não suportar e entrar em colapso desencadeando em cada mais catástrofes como se é noticiado em várias partes do mundo. 
Neste contexto, esses atores públicos, ainda se deparam com muitos aspectos que dificultam a aplicação das licitações sustentáveis, tais como a dificuldade da inserção dos critérios sustentáveis nas aquisições realizadas pelo setor público sem que se frustrem os princípios da competitividade, isonomia e economicidade; a necessidade de mudança cultural e conscientização da sociedade e principalmente dos servidores públicos; a insuficiência de normas que auxiliem a prática das aquisições públicas sustentáveis; a complexidade de aplicação dos dispositivos legais que as normatizam; a necessidade de realização de cursos de capacitação nessa área; e o alto preço dos produtos e serviços sustentáveis ainda praticados pelo mercado.

Diante dessas barreiras e da necessidade de se alterar uma realidade constituída, é que, em algumas vezes, torna-se o trabalho da Comissão Permanente de Licitação impactante no seu cumprimento.

Vale salientar também que o Plano de Logística Sustentável (PLS) do Tribunal de Justiça de Pernambuco, em conformidade com as recomendações do Conselho Nacional de Justiça, que editou a Resolução CNJ no 201/2015 (Brasil, 2015), dispondo que os órgãos do Poder Judiciário nacional criassem as unidades ou núcleos socioambientais em sua estrutura, inclusive com a implantação do Plano de Logística Sustentável (PLS-PJPE), tem orientado a busca por licitações sustentáveis em todo o âmbito do TJPE.

Dada à atualidade e relevância, o estudo se justifica, ainda, pelo fato de que irá proporcionar uma ferramenta para que o Tribunal de Justiça de Pernambuco consiga sistematizar suas ações no sentido de cumprir com a responsabilidade de promover desenvolvimento por meio das suas licitações, incorporando critérios socioambientais em suas aquisições e serviços, em busca constante pelo desenvolvimento sustentável, promovendo benefícios a sociedade, a economia e a instituição.

É inegável que investir em eficiência energética é a melhor forma de se contribuir com a conservação de energia e consequente mitigação das emissões de dióxido de carbono advindas da geração de energia elétrica por fontes térmicas que tem como combustível óleo, carvão e gás (ACEEE, 2018).

Com isso, no intuito de promover ações que busquem a minimização das emissões de $\mathrm{CO}_{2}$, através do uso da eficiência energética foram desenvolvidos no Departamento de Engenharia e Arquitetura do Tribunal de Justiça de Pernambuco para atender os requisitos em busca de licitações sustentáveis

\section{Fundamentação teórica}

A licitação sustentável pode ser definida como aquela que busca, em todas as suas fases; ou seja, desde a concepção do projeto a sua plena execução e funcionamento, minimizar os impactos ambientais é aquela que integra considerações socioambientais em todas as suas fases com o objetivo de reduzir impactos negativos sobre o meio ambiente. É importante também frisar que ela deve estar em consonância com o tripé econômico, social e ambiental.

O novo conceito de desenvolvimento sustentável obteve papel de destaque na nova regra, sendo um dos princípios destacados no Decreto: A nova norma destaca quatro dimensões da sustentabilidade. Além do tradicional tripé econômico, social, ambiental, acrescenta-se uma nova e importante dimensão que é a cultural.

A nova norma indica que a sustentabilidade seja avaliada em todas as etapas do processo e integrada ao planejamento como um todo - no mínimo, desde o Plano de Gestão de Logística Sustentável, que faz parte do planejamento estratégico da Administração. Ou seja, a sustentabilidade deve fazer parte de todas as etapas do processo de compra ou contratação.

No tocante ao pregão, vale a pena se aprofundar no Decreto no 10.024/2019 (Brasil, 2019), que regulamenta a licitação, na modalidade pregão, na forma eletrônica, 
para a aquisição de bens e as contratações de serviços no âmbito da administração pública federal.

É importante salientar a existência de diversos normativos, nacionais e estrangeiros, que impõem o respeito ao desenvolvimento sustentável, bem como a jurisprudência do TCU que aponta a necessidade de que os "Planos de Gestão de Logística Sustentável (PLS) estejam previstos no planejamento estratégico de cada órgão e entidade da Administração Pública Federal". De igual maneira, exige-se que sejam coordenadas "as iniciativas destinadas ao aprimoramento e à implementação de critérios, requisitos e práticas de sustentabilidade a serem observados pelos órgãos e entidades da administração federal em suas contratações públicas, nos termos do art. $2^{\underline{o}}$, do Decreto $\mathrm{n}^{\mathbf{0}}$ 7.746/2012" (Acórdão 600/2019-Plenário).

É urgente a mudança dessa cultura em todas as esferas do Poder Público. Para isso, a administração pública deve cada vez mais está alinha com os Objetivos de Desenvolvimento Sustentável, mais especificamente o ODS 12 que tem como meta "assegurar padrões de produção e de consumo sustentáveis".

\section{Tecnologia LED}

A busca pelas inovações tecnológicas voltadas para a eficiência energética, mais especificamente, no setor de iluminação resultou em grandes avanços ao longo dos anos. Constata-se que a sociedade passou pela fase das conhecidas lâmpadas incandescentes para as fluorescentes em um lapso temporal curto e mais curto ainda no tocante a nova realidade na tecnologia Light Emitter Diode (LED). Entende-se que é possível alcançar uma economia de energia de cerca de $30 \%$ por sistema de iluminação pública com o uso de tecnologias mais eficientes (ELETROBRAS, 2018). Ressalta-se também que se torna ainda mais fácil estabelecer os requisitos mínimos para iluminação recomendados pela norma regulamentadora NBR 5410:2004 (ABNT, 2004), na qual estabelece os requisitos mínimos para iluminação em ambientes de trabalho, propiciando conforto visual.

A tecnologia LED está cada dia mais se consolidando e já é realidade em residências, setores comerciais e industriais, iluminação pública, etc. Um dos principais pontos de destaque além da eficiência energética é a duração da tecnologia LED que pode chegar a 30 anos de garantia (Ascurra, 2013). Embora já esteve entre as desvantagens o custo inicial elevado, hoje em dia está cada vez mais acessível e o retorno do investimento está sendo em poucos meses. Ou seja, em poucos anos as lâmpadas LED terão grande espaço na sociedade ultrapassando as lâmpadas fluorescentes.

Outro fator importante a ser observado é a vida útil das lâmpadas que é o tempo em horas que a lâmpada deve funcionar de acordo com o fabricante, a relação entre as tecnologias presente no mercado e o tempo de vida útil. Esse é um dos fatores importantes na decisão da compra ou não de determinada lâmpada, pois o investimento inicial pode ser maior, mas com o tempo de vida útil da lâmpada e a eficiência o investimento inicial maior se torna plausível (Figura 1) (Giacomin, 2017).

Outro fato a ser levado em conta é que a quantidade de acionamentos influenciam na vida útil das lâmpadas incandescentes e fluorescentes, como descreve a pesquisa de sobre a relação da vida útil das lâmpadas incandescentes, fluorescente e LED de acordo com a quantidade de acionamentos (Oliveira, 2013).

Com o decorrer dos testes obtivemos até o momento a fadiga de 3 lâmpadas fluorescente e 3 lâmpadas incandescentes, com os tempos de 220,21 horas, 223,03 horas e 221,30 horas; para as lâmpadas fluorescentes submetidas ao estresse, 474,40 horas, e 479,54 horas para as lâmpadas incandescentes, com base no período definido empiricamente, e 482,12 horas para uma incandescente em estresse, sendo que, até o momento, nenhuma lâmpada LED demonstrou fadiga. Lembrando que a vida útil de 6000 horas para as fluorescentes e 1000 horas para 
as incandescentes, não foram atingidas. Podemos assim notar que foi significativa a redução da vida útil. Recomenda-se, em função dos resultados dos ensaios, que em locais com significativo número de acionamentos diários sejam utilizadas lâmpadas LED.

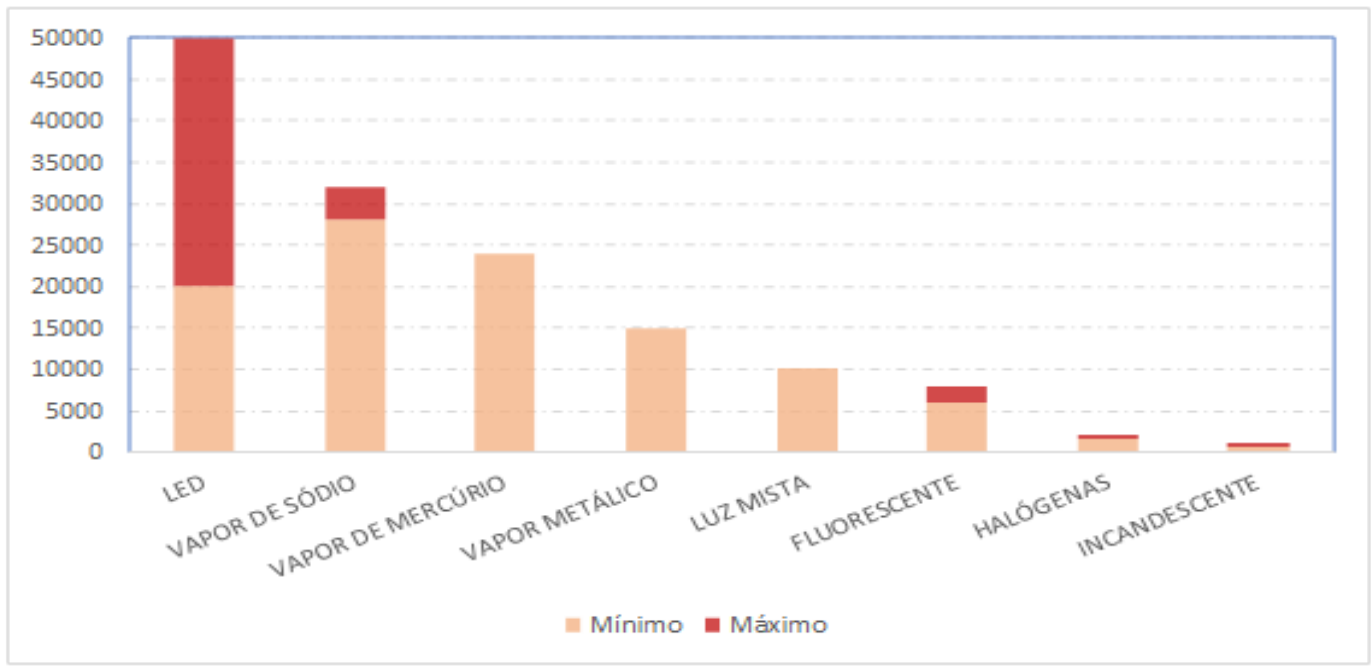

Figura 1. Durabilidade em horas das tecnologias das lâmpadas atuais. Fonte: (Cordeiro, 2015).

Logo, além do fato que a durabilidade das lâmpadas fluorescente diminuem com o acionamento deles, as lâmpadas LED se mostram ainda mais a melhor opção, porque não se desgastam com o acionamento" (Oliveira, 2013).

\section{Eficiência energética e tecnologias de lâmpadas}

Diante de um projeto de iluminação, o item que mais se destaca é a lâmpada. Por isso, é necessário que haja uma análise criteriosa em face da enorme quantidade de modelos e variações que existem no mercado (Gomes, 2017).

As lâmpadas que apresentam um filamento emitem luz pela incandescência, assim como a luz gerada pelo sol. Já as lâmpadas que são de descarga emitem luz em temperaturas relativamente baixas. A luz emitida pelos diodos, utiliza o fenômeno da fotoluminescência. Por sua vez, as lâmpadas mistas são chamadas assim porque combinam a incandescência e a luminescência, enquanto as lâmpadas fluorescentes combinam os fenômenos de luminescência e fotoluminescência.

\section{- Lâmpadas de descarga elétrica}

Nesse tipo de lâmpada o fluxo luminoso é gerado direta ou indiretamente pela passagem da corrente através de um gás, mistura de gases ou vapores. Apresentam os seguintes tipos:

\section{- Fluorescentes tubulares}

As lâmpadas tubulares têm uma aplicabilidade em várias áreas como nos comércios, indústrias e residências, uma vez que apresentam alta eficiência e longa durabilidade. Essas lâmpadas contêm em seu interior vapor de mercúrio e gases inertes. Com a passagem de corrente elétrica pelo seu interior, os elétrons chocam-se com os átomos de mercúrio, fornecendo energia aos seus elétrons, fazendo com que mudem de 
órbita e cheguem a uma camada mais externa. Quando esses elétrons retornam para a sua camada de origem, há a liberação de energia na forma de radiação ultravioleta, que é convertida em luz visível pela pintura fluorescente que reveste a parte interna do bulbo da lâmpada. A eficiência luminosa varia de $70 \mathrm{~lm} / \mathrm{W}$ e IRC 78, nas do tipo convencional. Já as do tipo trifósforo apresentam eficiência de $100 \mathrm{~lm} / \mathrm{W}$ e IRC 85.

\section{- Lâmpadas de LED}

Estas lâmpadas apresentam como características: menor potência; maior eficiência luminosa; maior IRC; menor fluxo luminoso comparado às lâmpadas fluorescentes e uma melhor expectativa de vida útil.

As lâmpadas do tipo LED comparadas com as antigas incandescentes apresentam uma eficiência seis vezes maior e com as fluorescentes compactas mais que o dobro. Quando se compara as lâmpadas LED com as do tipo halógenas tradicionais percebeu-se uma eficiência quase dez vezes. Já as LED tubulares possuem uma eficiência de mais que o dobro se compara as fluorescente tubulares tradicionais. Salienta-se também os benefícios à saúde do olho humano, já que a lâmpada LED não apresentada o efeito estroboscópico presente na tecnologia fluorescente.

\section{Tribunal de Justiça de Pernambuco}

A estruturação do Poder Judiciário no Brasil é fruto de um longo processo, que tem seu início desde a época das capitanias hereditárias, criado em 1534 por Dom João III. Da mesma forma como era concedido ao Rei o poder de fazer justiça, conforme as Ordenações Manuelinas e Filipinas, também lhe era permitido o "repasse da competência régia de fazer justiça". Na Capitania de Pernambuco, o Poder Judiciário foi inicialmente delegado ao capitão donatário, Duarte Coelho.

0 primeiro prédio destinado à Justiça de Pernambuco é o Palácio da Justiça, atual sede do Tribunal de Justiça do Estado de Pernambuco, que atua com as competências e a jurisdição determinadas pela Constituição Federal de 1988.

A Poder Judiciário de Pernambuco tem buscado prestar serviços de qualidade a sociedade. Com isso, concluiu recentemente a construção de doze prédios em diferentes comarcas do estado. Salienta-se que os prédios foram construídos buscando a sustentabilidade em diferentes quesitos, especialmente em eficiência energética, foco deste trabalho.

Para o Tribunal de Justiça, os prédios não são apenas mais imóveis construídos, mas a concepção de um Poder Judiciário rápido, eficiente, moderno e uma prestação jurisdicional de qualidade: o Judiciário do futuro.

Desta forma, esse trabalho irá se desenvolver em consonância com as atividades desenvolvidas pelo TJPE. O método de pesquisa empregado será o estudo de caso, especialmente no tocante a utilização das lâmpadas LED nas diversas unidades instaladas no TJPE.

\section{Metodologia}

A escolha dessa metodologia e análise segue todas as fases e metodologias do PROPEE do Programa de Eficiência Energética e estão alinhadas com os Objetivos de Desenvolvimento Sustentável (ODS), propostos pela Organização das Nações Unidas (ONU), mais especificamente e diretamente ligadas ao ODS 13 (Ação Contra a Mudança Global do Clima), bem como o ODS 7 (Energia Acessível e Limpa - Assegurar o acesso confiável, sustentável, moderno e a preço acessível à energia para todos) o ODS 11 (Cidades e comunidades sustentáveis - Tornar as cidades e os assentamentos humanos inclusivos, seguros, resilientes e sustentáveis) e, por fim com ODS 12 (Consumo e produção responsáveis - Assegurar padrões de produção e de consumo sustentáveis). 
Para um melhor entendimento da metodologia, faz-se necessário entender a estrutura do Poder Judiciário de Pernambuco (Figura 2).

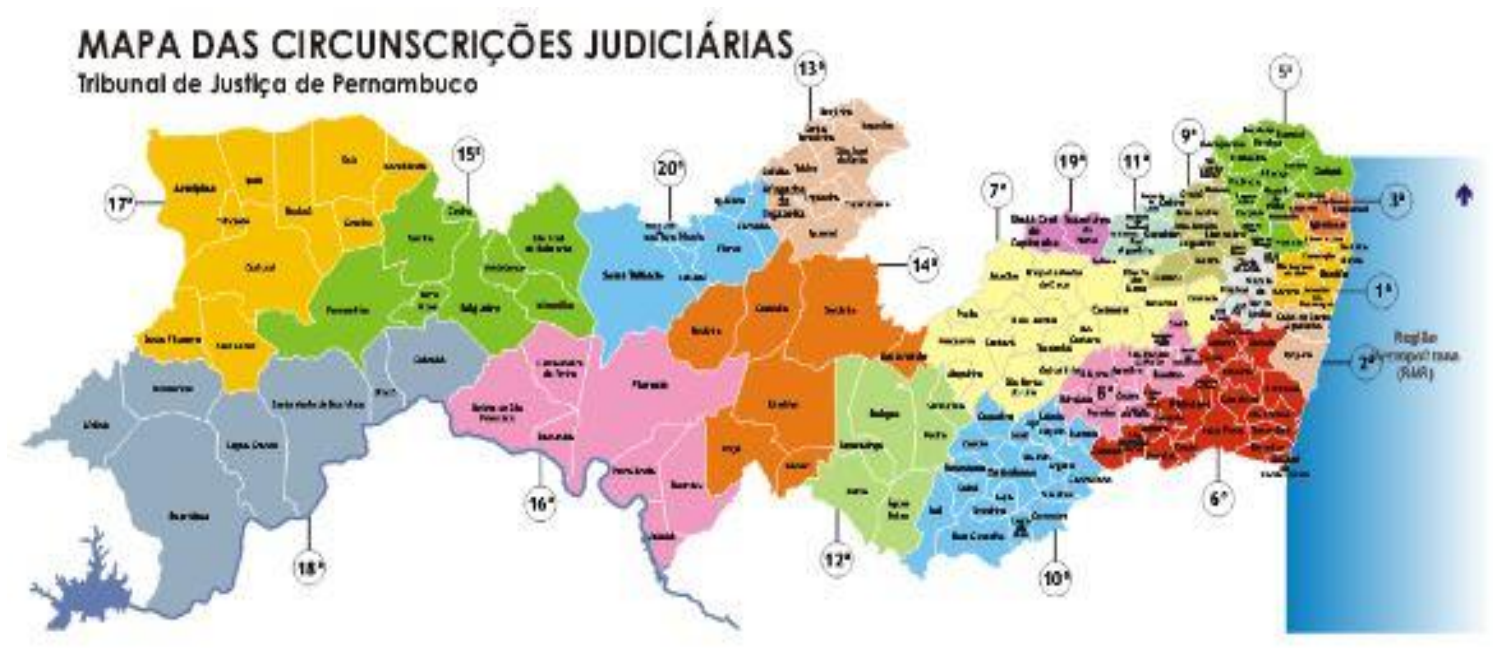

Figura 2 Mapa das circunscrições jurídicas. Fonte: TJPE.

O principal foco desse trabalho, é a análise econômica e ambiental após a substituição de lâmpadas de alguns prédios construídos no âmbito do Poder Judiciário, diante disso esta pesquisa se caracteriza quanto a sua natureza como sendo teóricoempírica. A pesquisa empírica, onde é necessária comprovação prática através de experimentos ou observação (Rampazzo e Corrêa (2008). Em relação à abordagem do problema a pesquisa se classifica como quantitativa, que conforme (Prodanov e Freitas, 2013, p. 69), "pesquisa quantitativa: considera que tudo pode ser quantificável, o que significa traduzir em números opiniões e informações para classificá-las e analisá-las".

Foram escolhidos 12 prédios construídos no período de 2016 a 2018 e posteriormente realizadas as análises abaixo.

\section{Avaliação financeira}

A análise de viabilidade econômica é a ferramenta essencial para analisar qualquer projeto quem tenha o intuito de se tornar executável, logo encontrar o melhor projeto mais eficiente possível no caso em que exista mais de uma alternativa mutualmente excludente, ou no caso individual do projeto, analisar a economia e em quanto tempo o investimento inicial dará retorno desejado.

Índices como Valor Presente Líquido, Tempo de Retorno de Capital (payback) (ELETROBRÁS, 2006) e Relação Custo Benefício são métricas essenciais para escolher a melhor alternativa. Essas ferramentas conseguem transformar os projetos em índices econômicos mostrando o quão atrativo o investimento é.

Saber o retorno do investimento feito inicialmente e em quanto tempo a melhor escolha se paga, ou seja, a opção pode ser mais cara a princípio pode sair como a mais barata com o passar do tempo devido a eficiência energética do projeto, consequentemente o custo total sairá mais barato a longo prazo quando se adicionar o gasto com energia ao preço do produto atual. Este capítulo é voltado para a viabilidade do investimento, logo os cálculos serão usados podem ser perfeitamente usados em licitações 
e concorrências públicas ou até análises simples de payback. Nos casos de necessidade de uso de taxa de juros, o valor de inflação de $8 \%$ ao ano será tomado como base, o que equivale a $0,6434 \%$ ao mês.

\section{Valor presente líquido}

O Valor Presente Líquido (VPL) também conhecido como Valor Atual Líquido (VAL) é uma fórmula que analisa a série de pagamentos futuros projetados no momento atual. Nesta análise, leva-se em conta os aspectos que diferenciam os projetos e não os aspectos em que os projetos são iguais, isso significa que o diferencial do projeto será traduzido no VPL, e na comparação entre dois projetos, o maior VPL representa o melhor custo benefício.

Esta formulação é ideal, pois leva em consideração o valor do dinheiro com o passar do tempo pois a quantia hoje não será a mesma futuramente devido no mínimo a inflação do país. Logo, a Taxa Mínima de Atratividade é usada para comparar investimentos, ela carrega o significado de no mínimo corrigir o valor do dinheiro devido ao tempo que passa. A formulação do cálculo do VPL é apresentada na Equação 1 (Soares, 2017).

$$
V P L=\sum_{n=0}^{N} \quad \frac{F C_{n}}{(1+T M A)^{n}}
$$

Onde: TMA - Taxa Mínima de Atratividade; n- periodicidade da análise

A interpretação do Valor Presente Líquido se dar inicial e basicamente no sinal de VPL, se positivo o investimento é bom, se negativo, a opção não é viável, em seguida analisar os valores de VPL, logo quanto maior o VPL melhor. Em $n$ igual a 0 corresponde ao investimento inicial que no caso entra no somatório como negativo.

\section{Tempo de retorno de capital}

O critério de tempo de retorno de capital, ou payback simples, resume-se em dividir o valor do investimento pelo valor de economia ou lucro sem considerar o horizonte de tempo logo o dinheiro perde seu valor com o passar do tempo. Essa análise é mais usada em primeira instância pois ela simplesmente esboça um cenário provável o que não a torna tão discrepante do Valor Presente Líquido. A fórmula do Payback simples está escrita na Equação 2 .

$$
\text { Payback } k_{\text {simples }}=\frac{\text { custo do investimento }}{\text { economia devido ao investimento }}
$$

\section{Relação custo benefício}

A Relação Custo Benefício (RCB) é uma relação que trata da razão entre o custo do projeto sobre o benefício que o projeto trará, quanto menor essa relação mais vantajosa o projeto. Também não leva em consideração a desvalorização da moeda com o tempo, é 
mais um indicativo numérico. A correta formulação que deve ser usada para submeter projetos de análise de eficiência energética é apresentada na Equação 3.

$$
R C B=\frac{\text { custodoinvestimento }}{\text { Benefíciodoprojetodurantesuavida útil }}
$$

\section{Equivalência de carbono}

Outra métrica importante e no caso mais verde é a equivalência da economia de energia elétrica $(\mathrm{kWh})$ em quilogramas de gás carbônico $\left(\mathrm{kgCO}_{2}\right)$ é apresentada na Equação 4 (Cordeiro, 2015).

$$
\text { ReduçãokgCO }{ }_{2}=\text { EconomiadeenergiakW } * \frac{0,47 \mathrm{kgCO}_{2}}{\mathrm{~kW} \text { [ }}
$$

\section{Resultados e discussão}

\section{Resultados ambientais}

A implementação da troca das lâmpadas fluorescentes por lâmpadas LED possibilitou a mitigação gases de efeito estufa (GEE), mais especificamente de milhares de toneladas de dióxido de carbono o que equivale a plantação de 500 árvores. Ressalta-se ainda que as lâmpadas ineficientes serão descartadas utilizando todos os padrões ambientais.

\section{Resultados sociais}

O projeto é visto como de grande relevância social, visto que a iluminação obtida pela iluminação externa possibilita a iluminação de toda a área do entorno, contribuindo diretamente com as Prefeituras das cidades para melhoria da qualidade de vida, especialmente à noite da população.

\section{Recuperação da gestão pública dedicada ao bem comum}

A iluminação com luminárias LED do tipo dimerizadas possibilita uma melhor iluminação no ambiente de trabalho dos mais de três mil servidores e mais de dez mil pessoas por dia que vão até estes prédios.

A dedicação de servidores públicos com foco na preservação ambiental, e mais especificamente nas licitações sustentáveis, demonstra a preocupação do Poder Judiciário Pernambucano com o alinhamento às temáticas do Plano de Logística Sustentável, cumprindo assim o papel do poder público em busca do desenvolvimento sustentável (Betiol et al., 2012; Alencastro et al., 2014).

É notório através da literatura que ainda não existe metas claras e apoio da administração público nesses sentido (Alencastro et al., 2014; Rocha, 2014). Ressalta-se também ainda a inexistência de estratégia ou metodologia para implementação das licitações sustentáveis (Generoso, 2014; Fernandes, 2016; Souza, 2016); bem como ainda é realidade a falta ou pouca adesão dos órgãos públicos às licitações sustentáveis (Fernandes, 2016). 
Porém, é preciso que casos de sucesso como esse implementado no TJPE, sejam replicados em outras esferas da administração pública, para que através das licitações sustentáveis a sociedade alcance excelência na área ambiental.

\section{Conclusão}

O poder público precisa estar cada vez mais alinhado com as metas de preservação ambiental. No tocante ao consumo de energia elétrica, constata-se um elevado potencial de conservação de energia que está diretamente ligado a mitigação das emissões de dióxido de carbono que tantos danos causa ao meio ambiente. Sendo assim, o investimento em inovações tecnológicas que visam à eficiência energética devem ser cada vez mais empregada em todas as esfera da sociedade, visto que atendem ao tripé ambiental, social e econômica da sustentabilidade.

O objetivo principal do trabalho foi avaliar o impacto da eficiência energética aplicando a conservação de energia nos novos prédios do TJPE. Foram enfatizados o sistema de iluminação com a troca da tecnologia de iluminação utilizada. Dessa forma, conclui-se que investir em eficiência energética pode trazer vários benefícios econômicos, pois, apresenta um retorno de investimento rápido (poucos meses); ambientais, pois contribui para diminuição da poluição ambiental melhorando a saúde da população que terá menos pessoas no setor público de saúde; e, por fim, social, pois, pode melhorar a integração com a sociedade e melhor a segurança pública das cidades.

Por fim, as propostas realizadas neste diagnóstico de eficiência energética oferecem excelentes oportunidades de redução do desperdício de mais $R \$ 700.000,00$ (setecentos mil reais) por ano, a mitigação de mais $1.000 \mathrm{t}$ de $\mathrm{CO}_{2}$, o que equivale à plantação de mais de 500 árvores por ano.

\section{Conflito de interesses}

Os autores declaram não haver conflito de interesses.

\section{Referências}

ABNT - Associação Brasileira de Normas Técnicas. ABNT NBR 5410:2004 - Instalações elétricas de baixa tensão. Rio de Janeiro: ABNT, 2004.

ACEEE - American Council for an Energy-Efficient Economy. The international energy efficiency scorecard. Washington, DC: ACEEE, 2018. Disponível em: <https://www.aceee.org/research-report/i1801>. Acesso em: 27 out. 2019.

Alencastro, M. A. C.; Silva, E. V.; Lopes, A. M. D. Contratações sustentáveis na administração pública brasileira: a experiência do Poder Executivo Federal. Revista de Administração

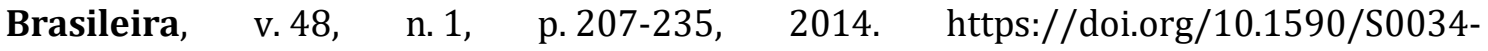
76122014000100009

Almeida, R.; Scatena, L.; Luz, M. Percepção ambiental e políticas públicas: dicotomia e desafios no desenvolvimento da cultura de sustentabilidade. Ambiente \& Sociedade, v. 20, n. 1. p. 43-64, 2017. https://doi.org/10.1590/1809-4422asoc20150004r1v2012017

Ascurra, R. E. Eficiência elétrica em iluminação pública utilizando tecnologia LED: um estudo de caso. Cuiabá: Universidade Federal de Mato Grosso, 2015. (Dissertação de mestrado).

Barbieri, J. S. Gestão ambiental empresarial: conceitos, modelos e instrumentos. 2. ed. São Paulo: Saraiva, 2007. 
Betiol, L. S.; Uehara, T.; Laloe, F. K.; Appugliese, G. A.; Adeodato, S.; Ramos, L. Mozoni Neto, M. P. Compras Sustentáveis: a força do consumo público e empresarial para uma economia verde e inclusiva. 1. ed. São Paulo: Gestão Pública e Cidadania, 2012.

Brasil. AGU - Advocacia-Geral da União. CGU - Consultoria-Geral da União. Guia nacional de licitações sustentáveis. Brasília: AGU, 2016. Disponível em: <http://www.agu.gov.br/page/download/index/id/33733269>. Acesso em: 21 set. 2019.

Brasil. Constituição da República Federativa do Brasil de 1988. Disponível em: $<$ http://www.planalto.gov.br/ccivil_03/Constituicao/Constituicao.htm>. Acesso em: 5 out. 2019.

Brasil. Lei no 8.666, de 21 de junho de 1993. Regulamenta o art. 37, inciso XXI, da Constituição Federal, institui normas para licitações e contratos da Administração Pública e dá outras providências. Disponível em: <http://www.planalto.gov.br/ccivil_03/leis/ l8666cons.htm>. Acesso em: 21 set. 2019.

Brasil. Lei no 10.295, de 17 de outubro de 2001. Dispõe sobre a Política Nacional de Conservação e Uso Racional de Energia e dá outras providências. Disponível em: <http://www.planalto.gov.br/ccivil_03/leis/leis_2001/L10295.htm>. Acesso em: 01 ago. 2019.

Brasil. Lei no 10.520, de 17 de julho de 2002. Institui, no âmbito da União, Estados, Distrito Federal e Municípios, nos termos do artigo 37, inciso XXI, da Constituição Federal, modalidade de licitação denominada pregão, para aquisição de bens e serviços comuns, e dá outras providências. Disponível em: <http://www.planalto.gov.br/ccivil_03/leis/2002/ L10520.htm>. Acesso em: 21 jul. 2019.

Brasil. Lei no 12.349, de 15 de dezembro de 2010. Altera as Leis nos 8.666,de 21 de junho de 1993, 8.958, de 20 de dezembro de 1994, e 10.973, de 2 de dezembro de 2004; e revoga o $\S 1^{\text {o }}$ do art. $2^{\text {o }}$ da Lei $n^{\circ} 11.273$, de 6 de fevereiro de 2006. Disponível em: $<$ http://www.planalto.gov.br/ccivil_03/_Ato2007-2010/2010/Lei/L12349.htm>. Acesso em: 21 set. 2019.

Brasil. Decreto no 4.059, de 19 de dezembro de 2001. Regulamenta a Lei no 10.295 , de 17 de outubro de 2001, que dispõe sobre a Política Nacional de Conservação e Uso Racional de Energia, e dá outras providências. Disponível em: <http://www.planalto.gov.br/ccivil_03/decreto/2001/D4059.htm>. Acesso em: 16 jul. 2019.

Brasil. Decreto no 4.131, de 14 de fevereiro de 2002. Dispõe sobre medidas emergenciais de redução do consumo de energia elétrica no âmbito da Administração Pública Federal. Disponível em: <http://www.planalto.gov.br/ccivil_03/decreto/2002/ D4131.htm>. Acesso em: 05 jul. 2019.

Brasil. Decreto no 5.450, de 31 de maio de 2005. Regulamenta o pregão, na forma eletrônica, para aquisição de bens e serviços comuns, e dá outras providências. Disponível em: <http://www.planalto.gov.br/ccivil_03/_ato2004-2006/2005/decreto/d5450.htm>. Acesso em 10 jun. 2019.

Brasil. Decreto no 7.746, de 05 de junho de 2012. Regulamenta o art. $3^{\circ}$ da Lei no ${ }^{\circ}$.666, de 21 de junho de 1993, para estabelecer critérios, práticas e diretrizes para a promoção do desenvolvimento nacional sustentável nas contratações realizadas pela administração pública federal, e institui a Comissão Interministerial de Sustentabilidade na Administração Pública - CISAP. Disponível em: <http://www.planalto.gov.br/ccivil_03/ _Ato2011-2014/2012/Decreto/D7746.htm>. Acesso em: 13 maio 2019. 
Brasil. Decreto no 10.024, de 20 de setembro de 2019. Regulamenta a licitação, na modalidade pregão, na forma eletrônica, para a aquisição de bens e a contratação de serviços comuns, incluídos os serviços comuns de engenharia, e dispõe sobre o uso da dispensa eletrônica, no âmbito da administração pública federal. Disponível em: <http://www.planalto.gov.br/ccivil_03/_ato2019-2022/2019/decreto/D10024.htm>.

Acesso em: 5 out. 2019.

Brasil. Ministério do Meio Ambiente. Compras públicas sustentáveis. 2019. Disponível em: <http://www.mma.gov.br/responsabilidadesocioambiental/a3p/eixos-

tematicos/licitaçãosustentável>. Acesso em: 20 ago. 2019.

Brasil. Ministério do Planejamento, Orçamento e Gestão. Secretaria de Logística e Tecnologia da Informação-SLTI. Planos de gestão de logística sustentável: contratações públicas sustentáveis. Brasília: MPOG/SLTI, 2014. (Caderno de Estudo e Pesquisa, 1; Política Pública de Sustentabilidade).

Brasil. Resolução CNJ no 201, de 3 de março de 2015. Dispõe sobre a criação e competências das unidades ou núcleos socioambientais nos órgãos e conselhos do Poder Judiciário e implantação do respectivo Plano de Logística Sustentável (PLS-PJ). Disponível em: <https://atos.cnj.jus.br/atos/detalhar/2126>. Acesso em: 10 abr. 2020.

Bursztyn, M. A. A.; Bursztyn, M. Desenvolvimento sustentável: Biografia de um conceito. In: Nascimento, E. P.; Vianna, J. N. S. (Org.). Economia, meio ambiente e comunicação. Rio de Janeiro: Garamond, 2006.

Cordeiro L. F. A. Eficiência energética no planejamento do setor elétrico com foco nas emissões de $\mathrm{CO}_{2}$. Florianópolis: Instituto IDEAL, 2015. (Eco_Lógicas: Concurso LatinoAmericano de Monografias sobre Energias Renováveis e Eficiência Energética).

Cordeiro, L. F. A. Planejamento do setor elétrico brasileiro com foco nas emissões de CO$_{2}$. Recife: Universidade Federal de Pernambuco, 2015. (Tese de doutorado).

Cypreste, A.S.T. Licitações sustentáveis, instrumento legal de promoção da sustentabilidade: um estudo da aquisição de bens na Universidade Federal do Espírito Santo - UFES. Vitória: Universidade Federal do Espírito Santo, 2013. (Dissertação de mestrado).

ELETROBRAS - Centrais Elétricas Brasileiras S. A. PROCEL. Resultado PROCEL 2018. Disponível em: <https://eletrobras.com/pt/Paginas/Procel.aspx>. Acesso em $10 \mathrm{abr}$. 2020.

Fernandes, H. A utilização de critérios de sustentabilidade ambiental em licitações realizadas por órgãos públicos federais sediados em Florianópolis-SC no biênio 2015/2016. Florianópolis: Universidade Federal de Santa Catarina, 2016. (Trabalho de conclusão de curso).

Generoso, G. B. M. Estudo do processo de compras da UFMG, no contexto da adoção de critérios de sustentabilidade ambiental. Pedro Leopoldo: Faculdades Pedro Leopoldo, 2014. (Dissertação de mestrado).

Giacomin, R. F. Eficiência energética das tipologias representativas de edifícios residenciais de um bairro à luz do PBE Edifica. Vitória: Universidade Federal do Espirito Santo, 2017. (Dissertação de mestrado).

Gomes, A. F. Eficiência energética em edificações públicas do poder executivo federal: oportunidades e desafios no contexto do Programa Brasileiro de Etiquetagem (PBE - Edifica). Brasília: Universidade de Brasília, 2017. (Dissertação de mestrado). 
Mendes, D. G. P. S. Compras sustentáveis no setor público: a integração de critérios ambientais, sociais e econômicos ao processo de aquisição de bens e serviços da Justiça do Trabalho. Recife: Universidade de Pernambuco, 2014. (Dissertação de mestrado).

Oliveira, I. P. Eficiência energética em sistemas de energia elétrica: um estudo de caso em uma indústria de lubrificantes. Campo Grande: Universidade Federal de Mato Grosso do Sul, 2015. (Dissertação de mestrado).

Pernambuco. TJPE - Tribunal de Justiça de Pernambuco. Disponível em: <https://www.tjpe.jus.br/>. Acesso em: 10 abr. 2020.

Prodanov, C. C.; Freitas, E. C. Metodologia do trabalho científico: métodos e técnicas da pesquisa e do trabalho acadêmico. 2. ed. Novo Hamburgo: FEEVALE, 2013.

Rampazzo, S. E.; Corrêa, F. Z. M. Desmistificando a metodologia cientifica: guia prático para a produção de trabalhos acadêmicos. 1. ed. Erechim: Hadilis, 2008.

Rocha, A. P. M. Sustentabilidade nas compras públicas: um estudo de caso numa unidade hospitalar do Estado de Pernambuco. Recife: Universidade Federal de Pernambuco, 2014. (Dissertação de mestrado).

Roncaligio, C.; Janke, N. Desenvolvimento sustentável. Curitiba: IESDE Brasil, 2018.

Souza, C. O. Compras públicas sustentáveis: um estudo de caso do processo decisório em órgãos federais do Rio de Janeiro. Rio de Janeiro: Fundação Getúlio Vargas, 2016. (Dissertação de mestrado).

Vargas, M. C.; Maestria, M. Eficiência energética em edificações residenciais: iluminação e refrigeração. Anais do XXXV Encontro Nacional de Engenharia de Produção, Fortaleza, 2015. Disponível em: <https://www.voltimum.com.br/sites/www.voltimum.com.br/files/ pdflibrary/ee_iluminacaorefrigeracao_2015.pdf>. Acesso em: 13 jun. 2020.

Informação da Licença: Este é um artigo Open Access distribuído sob os termos da Licença Creative Commons Attribution, que permite uso irrestrito, distribuição e reprodução em qualquer meio, desde que a obra original seja devidamente citada. 